Laboratorio de Arte,4-1991 http://dx.doi.org/10.12795/LA.1991.i04.23

\title{
UN NIÑO JESÚS DEL ESCULTOR GABRIEL DE ASTORGA
}

\author{
por José Roda PeÑa
}

\begin{abstract}
Damos a conocer una obra inédita que viene a engrosar el catálogo del escultor decimonónico sevillano Gabriel de Astorga y Miranda. Se trata del Niño Jesús fechado en 1871 que posee la Hermandad de Pasión, que en su iconografia comparte atributos pasionarios con los del Sagrado Corazón de Jesús.
\end{abstract}

Si siempre resulta gratificante dar a conocer una obra que hasta el presente se hallaba sin documentar, la satisfacción se incrementa cuando el hallazgo contribuye al mejor conocimiento de la producción de un artífice, cuyo catálogo de realizaciones no es demasiado extenso. Este es el caso de Gabriel de Astorga y Miranda, segundo hijo del afamado Juan de Astorga, quien sin duda es el más cualificado de los escultores que laboraron en la Sevilla de la primera mitad del siglo XIX.

Pocos son los datos biográficos que conocemos de Gabriel de Astorga. De entre los mismos, recordaremos que nació en Sevilla en 1804; fue recibido junto a su padre como miembro de la Hermandad del Santo Entierro en $1826^{1}$. Un año después, y merced a la posición paterna en la Real Escuela de las Tres Nobles Artes en la que desempeñaba el cargo de Director de Escultura, ingresará en dicha sección como Profesor Ayudante; en 1829, 1830 y 1844 recibió premios de la citada Escuela por su labor escultórica ${ }^{2}$. En 1837 intentó, sin conseguirlo,

1. RUIZ ALCAÑIZ, José Ignacio: El escultor Juan de Astorga. Sevilla, 1986, pp. 13 y 15.

2. MURO OREJÓN, Antonio: Apuntes para la Historia de la Academia de Bellas Artes en Sevilla. Sevilla, 1961, pp. 48 y 54-56. 
obtener el cargo de Director de Escultura en la Academia Provincial de Bellas Artes de Cádiz ${ }^{3}$. En Sevilla, fue nombrado académico de mérito en abril de 1848 , y a la muerte de su padre en 1849 , ascendió al cargo de Director interino de Escultura. Una vez fallecido su protector, su buena fortuna en la nueva etapa iniciada por la ya Real Academia de Bellas Artes de Santa Isabel de Hungría de Sevilla cayó en picado. Tan es así, que en 1855 perdió la votación verificada para elegir una plaza de profesor de escultura, que ganaría Leoncio Baglieto ${ }^{4}$.

Gabriel de Astorga, a pesar de ser el discípulo más aventajado que tuvo su propio padre, no logró nunca alcanzar las calidades técnicas y estéticas de su maestro ${ }^{5}$. Estilísticamente, se desenvolverá en la órbita del eclecticismo imperante en la segunda mitad del Ochocientos, con claro predominio de la poética neoclásica y posromántica. No podemos considerarlo creador de tipos iconográficos, al menos en lo hasta ahora conocido de su obra, ya que repite modelos conocidos en el taller paterno, cuando no los consagrados ampliamente por la escuela sevillana de imaginería. A pesar de todo ello, no debemos negarle una indudable personalidad propia en la consecución de sus esculturas, que las hace fácilmente reconocibles al repetir similares rasgos morfológicos; asimismo, posee habilidad en el dibujo y en el modelado, dotando a sus imágenes de cierta dignidad, aun dentro de la mediocridad en la que se encuentra inmersa la escultura sevillana de este período, que sólo encontrará un "redentor" en la encomiable figura de Antonio Susillo.

El quehacer escultórico de Gabriel de Astorga se centra fundamentalmente en la imaginería religiosa de bulto redondo, con predominio de las efigies procesionales de candelero para vestir. Citemos, de entre su producción más conocida, la Virgen de la Soledad del Convento de San Buenaventura $-1851-{ }^{6}$, la Divina Pastora de la Real Parroquia de Santa Ana ${ }^{7}$, el San Juan Evangelista de la

3. BANDA Y VARGAS, Antonio de la: "Datos para la Historia de la Escultura sevillana del siglo XIX", en Boletín de Bellas Artes, n. ㅈ. Sevilla, 1981, pp. 185-191. El fallo del tribunal juzgaba los dos dibujos presentados a la oposición por Gabriel de Astorga en los siguientes términos: "No hallamos en estos ensayos o primeros dibujos de prueba a la oposición, ninguna de aquellas señales artísticas o científicas ni prácticas que garanticen de lleno el desempeño de la Dirección de Escultura y consiguientes estudios del Dibujo en esta academia" (p. 166).

4. MURO OREJÓN, Antonio: Apuntes para la Historia... Op. cit., pp. 49, 72 y 147.

5. BANDA Y VARGAS, Antonio de la: "La imaginería procesional sevillana en los siglos XIX y XX", en Boletín de las Cofradías de Sevilla, n. ${ }^{242}$. Sevilla, noviembre de 1979, p. 19; RUIZ ALCAÑIZ, José Ignacio: El escultor Juan de Astorga. Op. cit., p. 25; BERNALES BALLESTEROS, Jorge: "Notas sobre las Cofradias en el siglo XIX (y VI)", en Diario $A B C$. Sevilla, 20 de marzo de 1986, p. 70; GONZÁLEZ GÓMEZ, Juan Miguel: "Imágenes de las Cofradías sevillanas desde el Academicismo al Expresionismo realista", en Las Cofradias de Sevilla en el Siglo de las Crisis. Sevilla, 1991, p. 114; BANDA Y VARGAS, Antonio de la: De la llustración a nuestros días en Historia del Arte en Andalucía. Vol. VIII. Sevilla, 1991, p. 188.

6. GONZÁLEZ DE LEÓN, Félix: Historia crítica y descriptiva de las cofradías de penitencia, sangre y luz, fundadas en la ciudad de Sevilla. Sevilla, 1852, pp. 197-199; BERMEJO Y CARBALLO, José: Glorias Religiosas de Sevilla. Sevilla, 1882, pp. 511-512.

7. MARTÍNEZ ALCALDE, Juan: Hermandades de Gloria de Sevilla. Sevilla, 1988, p. 63. Al parecer, la imagen fue transformada en Divina Pastora sobre una efigie original de Gabriel de Astorga. 
Hermandad de Pasión $-1862-{ }^{8}$, todas ellas en la capital hispalense, o la Virgen de la Esperanza de la ermita de Nuestra Señora del Valle en Hinojos (Huelva) $-1864-{ }^{9}$ y las efigies de la Virgen de las Angustias y San Juan Evangelista del templo de San Pedro Mártir en Marchena -1867- ${ }^{10}$. Igualmente, sabemos que ejecutó una réplica de la sevillana Virgen de las Fiebres, para el Seminario de San Juan de Puerto Rico "'.

No le fue ajena la labor restauradora, sobresaliendo las intervenciones que verificó sobre esculturas tan conocidas como el Cristo de la Conversión del Buen Ladrón de Juan de Mesa en $1851^{12}$, el gótico Crucificado de San Agustín ese mismo año ${ }^{13}$, las tallas de Pedro Nieto del misterio del Descendimiento de la Hermandad de la Quinta Angustia en $1854^{14}$, la Virgen de la Merced de la Hermandad de Pasión en $1872^{15}$, o la venerada Virgen de Loreto, titular del santuario de Espartinas ${ }^{16}$.

La escultura inédita que ahora presentamos es un Niño Jesús de madera policromada, tallado en su integridad, concertado en 1871 por la Hermandad de Pasión radicada desde 1868 en la parroquial hispalense del Divino Salvador. Ya hemos visto cómo Gabriel de Astorga Miranda había trabajado con anterioridad para la citada corporación hispalense, pues en 1862 dona la efigie de San Juan Evangelista que acompaña procesionalmente a Nuestra Madre y Señora de la Merced en su salida penitencial del Jueves Santo ${ }^{17}$. Nueve años más tarde ejecu-

8. GONZÁLEZ GÓMEZ, Juan Miguel: "Imágenes de las Cofradías sevillanas desde el Academicismo al Expresionismo realista". Op. cit., pp. 158-159. Está firmado y fechado en el pecho.

9. GONZÁLEZ GÓMEZ, Juan Miguel y Manuel CARRASCO TERRIZA: Escultura Mariana Onubense. Huelva, 1981, pp. 90-91. Aparece firmada y fechada en la base del candelero.

10. AA. VV.: Inventario artístico de Sevilla y su provincia. T. II. Madrid, 1985, p. 81.

11. MARTíneZ ALCALDE, Juan: "La Virgen de las Fiebres, en Puerto Rico" en Boletín de las Cofradías de Sevilla, n. ${ }^{-365}$. Sevilla, febrero de 1990, p. 61. Fue encargada por el malagueño fray Pablo Benigno Carrión cuando fue nombrado obispo de Puerto Rico. Actualmente, se encuentra depositada en el Instituto de Cultura Portorriqueña.

12. BERMEJO Y CARBALlO, José: Glorias Religiosas de Sevilla. Op. cit., p. 309. Encarnó de nuevo la imagen y le colocó ojos de cristal.

13. CARRERO RODRÍGUEZ, Juan: Anales de las Cofradias Sevillanas. Sevilla, 1991, p. 555.

14. Ibidem, p. 293.

15. RODA PEÑA, José: "Antiguas imágenes titulares de las Cofradías sevillanas", en Las Cofradias de Sevilla en el Siglo de las Crisis. Sevilla, 1991, p. 227.

16. CASTILlo UTRILlA, María José: "La iglesia y el Colegio de San Buenaventura de Sevilla en el siglo XIX”, en Laboratorio de Arte n.. 1. Sevilla, 1988, p. 185. En el manuscrito escrito por Fray Atanasio López de Vicuña en 1897 , se dice textualmente: “... donde hoy está la Soledad, preciosa escultura hecha hacia 1840 por Astorga, que también retocó a la Virgen de Loreto y le puso los ángeles que compró para ella Doña Manuela lllanes, que vivía en el Loreto con el Padre Miguelito."

17. (A)rchivo de la (H)ermandad (S)acramental de (P)asión de (S)evilla. Sección Pasión. Leg. 5. Secretaría 1793-1900. Carpeta 15. Consta que la imagen se bendijo por el presbítero D. Félix Tristán el 13 de abril de 1862; Leg. 30. Mayordomía 1861-1880. Carpeta 30-1. Data de las Cuentas de 1862, s. f. "Para Astorga para completar el obsequio que por varios hermanos se hizo a dicho Señor, recompensa del San Juan que regaló a la corporación, 200 reales"; Leg. 120. Libro 3. ' de Acuerdos 1857-/884. Junta de Oficiales del 12 de abril de 1862, f. $61 r$. "En este año ha hecho con una pompa y suntuosidad extraordinaria estación nuestra Hermandad, como lo tiene 
tará para la misma la talla del aludido Niño Jesús, por un importe de mil reales de cuya entrega firma recibo el 28 de octubre de $1871^{18}$. Meses después, en marzo de 1872, se documenta la última labor de Gabriel de Astorga para la Cofradía de Pasión. Nos referimos a la ya citada restauración de la imagen titular mariana, por la que percibió 400 reales ${ }^{19}$.

La escultura del Niño Jesús mide $68 \mathrm{cms}$. de alto y reposa sobre un escabel en forma de abultada nube, tachonada en su parte delantera por una cabeza alada de querube. Sabemos que esta nube fue estofada en 1897 por el notable imaginero Manuel Gutiérrez Reyes y Cano, quien además restauraría la propia efigie infantil ${ }^{20}$. El pequeño Jesús se muestra erguido y en dinámica actitud descargando todo el peso sobre la pierna izquierda, al par que la derecha se retrasa un poco quedando el pie levantado y apoyado en una protuberancia de la nube. La anatomía infantil está modelada con formas regordetas y un tanto achaparradas. La desnudez del Niño queda tan sólo encubierta por un escueto paño de pureza de perfil triangular. En sus manos porta atributos de la Pasión. La izquierda se alza para sostener el "stipes" plateado de la Cruz redentora, mientras el brazo diestro permanece bajo portando en la mano la rizada corona de espinas con los tres clavos del martirio. En su pecho asoma el flameante corazón henchido de amor por la humanidad. La cabeza se alza para dirigir la mirada al cielo. El rostro es muy característico de su producción, de contornos redondos y muy ancho. Posee cejas rectas, ojos de cristal que carecen de pestañas postizas, nariz corta y respingona, labios entreabiertos dejando al descubierto la hilera superior de dientes y cuello escasamente anatomizado. La cabellera se trabaja con minuciosidad, a base de ensortijados bucles que llegan a cubrir los pabellones auditivos. La testa se orla con tres potencias de metal dorado y corte decimonónico.

Usualmente la imagen se presenta vestida con suntuosos trajes bordados o lisos, ceñidos por cordón a la cintura. Las zonas de encarnadura que se encuentran cubiertas ostentan tonos pálidos acordes con el ideal clasicista practicado por su autor. Las partes descubiertas están muy oscurecidas por la materia inerte

\footnotetext{
de costumbre. Se ha estrenado la efigie del San Juan, hecha por el célebre escultor D. Gabriel Astorga, el cual hizo donación de ella a la Corporación y ésta en agradecimiento a dicha oferta acordó se le pasase una atenta comunicación dándole las gracias, lo que se verificó".

18. A.H.S.P.S. Sección Pasión. Leg. 30. Mayordomía 1861-1880. Carpeta 30-3. Cuentas de 1871-2. En la Data, s. f. aparece: "Por la escultura del Niño Jesús que se venera en los altares de la hermandad, según n.o 13, 1.000 reales". El recibo n. ${ }^{9} 13$ dice así: "Recibí del Sr. D. Manuel Balenzuela mil reales por un niño Dios de escultura en madera que he hecho a dicho señor. Sevilla, 28 de octubre de 1871. Gabriel de Astorga y Miranda (rúbrica)". A la sazón, Manuel Valenzuela era el Mayordomo de la Hermandad.

19. Ibidem, recibo n. .29 firmado el 3 de marzo de 1872 .

20. A.H.S.P.S. Sección Pasión. Leg. 31. Mayordomia 1881-1898. Carpeta 31-4. Cuentas de 1897-8, recibo n. ${ }^{\circ}$ 26. "Manuel Gutiérrez R. y Cano. Escultor. San Vicente, 7. Sevilla (encabezamiento). Recibí del Sr. Mayordomo de la Hermandad y Cofradía de Ntro. Padre Jesús de la Pasión la cantidad de doscientos cuarenta reales por la restauración de un Niño de la misma, y estofado completo de la nube. Sevilla y agosto 22 de 1897 . Manuel Gutiérrez R. Cano (rúbrica)".
} 
acumulada y el humo de las velas. Asimismo, hay pequeñas lagunas de la película pictórica en la peana y manos del Niño, existiendo la pérdida de tres dedos en la izquierda.

En 1878 unos hermanos le donaron una esbelta peana de estilo neobarroco ${ }^{21}$, conservada aún en la actualidad, sobre la que se coloca la efigie en los cultos penitenciales de la Hermandad, en el centro de la mesa de gobierno. El resto del año la imagen permanece en la Sala Capitular. Primitivamente estuvo colocada dentro de una urna situada entre los altares de San Fernando y San Cristóbal, donde se veneraban los titulares de la corporación ${ }^{22}$.

Por último, anotar que desde el punto de vista iconográfico la fórmula del Sagrado Corazón de Jesús Niño era ya conocida en la Sevilla tardobarroca. Cristóbal Ramos la empleó en el Niño que forma parte del grupo de la Divina Pastora de la parroquia de la Inmaculada Concepción de Galaroza (Huelva) ${ }^{23}$. El Padre Ardales apunta que este motivo pudo ser tomado por Ramos de un grabado del italiano Mannelli ${ }^{24}$. Además, Gabriel de Astorga debió conocer el tema en el taller paterno, si aceptamos la atribución que Ruiz Alcañiz le hace del Sagrado Corazón de Jesús, que con forma de Buen Pastor recibe culto en la Capilla Sacramental de la iglesia de Nuestra Señora de la Antigua de Almensilla ${ }^{25}$.

A nuestro juicio, pensamos que en el caso que nos ocupa, Gabriel de Astorga se limitó a copiar el modelo iconográfico que le suministraba un Niño Jesús anónimo que la Hermandad de Pasión poseía, al menos desde que residía en la parroquia de San Miguel. Al respecto, hemos encontrado en las cuentas de 1868 un gasto de 300 reales "por la adquisición de la lámina del Niño Jesús, que se veneraba en San Miguel y hoy en nuestros altares", así como un recibo de 57 reales del mismo año "por cien estampas del Niño del Corazón de Jesús" 26. Ese Sagrado Corazón de Jesús Niño también ostentaba atributos pasionistas, pues en 1870 el platero José de Giuli le ejecuta una $\mathrm{Cruz}^{27}$.

21. A.H.S.P.S. Sección Pasión. Leg. 30. Mayordomía 1861-1880. Carpeta 30-4. Cuentas de 1877-8, recibo n.o 44.

22. A.H.S.P.S. Leg. I. Inventarios. Carpeta 1-4. Inventario del 30 de noviembre de 1875 , s. f. "En el centro de los dos altares (Cristo y Virgen), una urna con el Niño Jesús con sus ropas de diario".

23. GONZÁLEZ GÓMEZ, Juan Miguel y Manuel CARRASCO TERRIZA: Escultura mariana onubense. Op. cit., p. 389.

24. ARDALES, Juan Bautista de: La Divina Pastora y el Beato Diego José de Cádiz. Sevilla, 1949, p. 411.

25. RUIZ ALCAÑIZ, José Ignacio: El escultor Juan de Astorga. Op. cit., p. 42.

26. A.H.S.P.S. Sección Pasión. Leg. 30. Mayordomía 1861-1880. Carpeta 30-2. Cuentas de 1868-9. Data, s. f. y recibo n. ${ }^{9}$, firmado por José Escobar el 14 de diciembre de 1868.

27. Ibidem. Cuentas de 1869-1870, recibo n. ${ }^{2} 28$. Firmado el 17 de enero de 1870. 


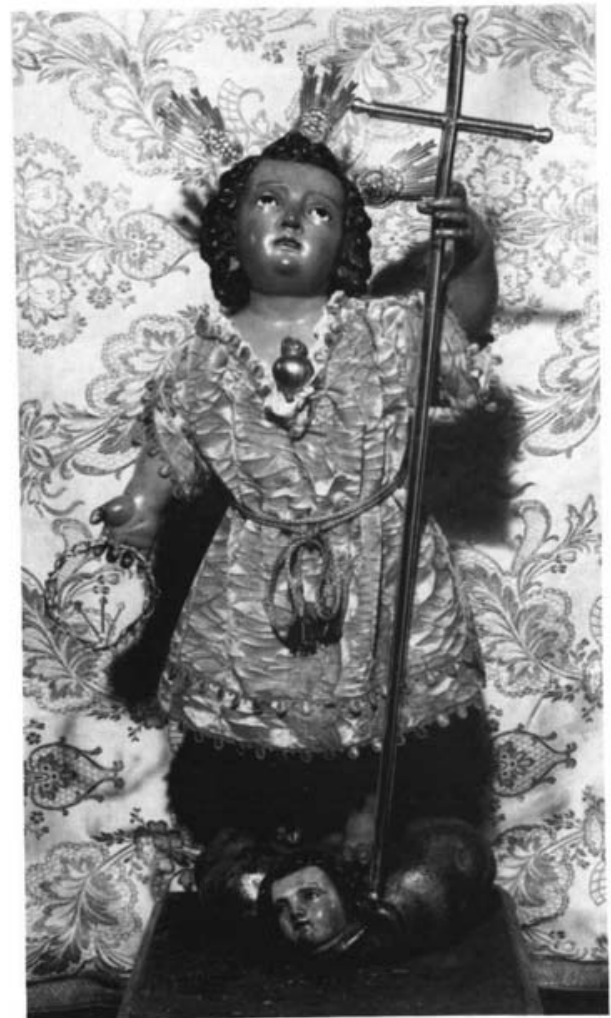

Nin̄o Jesús, Gabriel de Astorga (187/). Hermandad de Pasión. Sevilla. 